\title{
Electrospun Polyurethane/Loess Powder Hybrids and Their Absorption of Volatile Organic Compounds
}

\author{
Jun Cong Ge, Jeong Hyeon Kim, and Nag Jung Choi \\ Division of Mechanical Design Engineering, Chonbuk National University, 567 Baekje-daero, Jeonju-si, \\ Jeollabuk-do 561-756, Republic of Korea \\ Correspondence should be addressed to Nag Jung Choi; njchoi@jbnu.ac.kr
}

Received 21 January 2016; Revised 19 February 2016; Accepted 24 February 2016

Academic Editor: Antonio Riveiro

Copyright (C) 2016 Jun Cong Ge et al. This is an open access article distributed under the Creative Commons Attribution License, which permits unrestricted use, distribution, and reproduction in any medium, provided the original work is properly cited.

\begin{abstract}
We investigated the effects of composite electrospun polyurethane (PU)/loess powder (LP) fibers for absorption of volatile organic compounds (VOCs) from air. PU films containing different amounts of LP $(0,10,30$, and 50 wt\% LP with respect to PU) nanoparticles (NPs) were analyzed using FE-SEM, FTIR, and XRD experimental analyzers. Electron microscopy and spectroscopy indicated that the proper content of LP NPs is homogeneous dispersion in a polymer matrix. In addition, $50 \mathrm{wt} \%$ of LP results in a higher concentration spinning nanosuspension that leads to some agglomeration on the film surface. The chloroform, benzene, and toluene (VOCs) absorption capacity of PU/LP composite films showed a trend of toluene $>$ benzene $>$ chloroform. The highest VOC absorption capacity was found with PU composite mats containing $30 \mathrm{wt} \% \mathrm{LP}$ NPs. The high VOC absorption capacity of PU/LP composite films can be used to remove VOCs from a new house or car.
\end{abstract}

\section{Introduction}

Electrospinning is an important method used to produce nanofibers with polymer solutions [1-4]. In the last 10 years, electrospinning has become one of the most important academic techniques in the fields of materials and technology. Because of its easy manufacturing process, low pollution, and low cost, electrospinning has been widely used in many fields. For example, electrospinning has been used with artificial skin, bandages, bulletproof clothing, battery electrolytes, sensors, and other biomaterials [5-11]. The simple one-step electrospinning process is fast developing in the past two decades. In one way, different types of complicated electrospinning processes include coaxial electrospinning [12], side-by-side electrospinning [13], and triaxial electrospinning [14]. In another way, different kinds of working fluids have been tried on these processes, including polymeric solutions, codissolving solutions of polymers and the functional ingredients, microemulsions, and also nanosuspensions. Electrospinning is a fiber spinning technology that injects charged polymer solution through a syringe pump under a highvoltage electrostatic field to form fibers. Under voltage in the nozzle, macromolecule droplets are affected by droplet surface tension. Surface tension direction is directed opposite to the electric field force, and the electric field induces charge at the macromolecule droplet surface. A Taylor cone is created when voltage slowly increases, causing macromolecule droplets to stretch from spherical to long and tapered. When the electric field strength increases to a critical value, the surface tension of the liquid is overcome by electrostatic force, and the liquid is ejected from the Taylor cone. With a strong electric field, the ejected liquid fluid is elongated, and a large amount of injected solvent evaporates, thereby causing a nanoscale fiber to form on the collector [15-17].

The nanometer fibers and nanometer fiber membranes produced by electrospinning technology have large specific surface areas and porosity, enabling good performance in many fields. These nonwoven fabrics have recently emerged as effective membranes for removing harmful water and airborne contaminants from the environment [18-21]. Filter media can protect people from both natural and man-made contaminants by filtering or absorbing hazardous materials. The main outdoor sources of volatile organic compounds (VOCs) are fuel combustion, transport of industrial waste gas such as car exhaust, and photochemical pollution. Indoors, VOCs mainly come from coal and natural gas combustion 
products, such as smoking, heating, and cooking, building and decoration materials, furniture, and cleaners [22, 23]. The harm of VOCs is obvious, as they cause headache, nausea, vomiting, and limb weakness. In severe cases when VOC concentration exceeds a certain threshold, convulsions, coma, and memory loss can result. Many researchers are interested in the absorption of VOCs by electrospun nanofibers. Scholten et al. [24] reported that electrospun polyurethane (PU) fiber can be effectively used to absorb VOCs from air. PU fibers demonstrated completely reversible absorption and desorption, with desorption obtained by simple purging with nitrogen at room temperature. Kim et al. [23] showed that PU fibers with $30 \mathrm{wt} \%$ fly ash had the highest VOC absorption capacity, which was 2.52-2.79 times greater than that of pristine PU fibers.

Porous clay materials are attractive candidate adsorbents for VOC removal [25-27]. Loess powder (LP) is used to purify water and can be used to adsorb many kinds of heavy metals and organic compounds from water. LP mainly consists of silicate, ferric oxide, and aluminum oxide; is a low cost, nontoxic, environmentally friendly material; and can be easily obtained, making it suitable for use as an adsorbent [28-32]. Some research has shown that clay can be used as an additive to load into polymeric fibers by electrospinning, but information on the absorption of VOCs is limited. In this study, LP is used as an adsorbent loaded into PU fibers by electrospinning to adsorb VOCs. This study also aims to investigate the possibility of LP utilization as an adsorbent for the removal of VOCs from air. This presents a new direction in the fields of environmental science and technology.

\section{Experimental Details}

2.1. Materials. PU pellets (Estane ${ }^{\circledR}$ Skythane $^{\circledR}$ X595A-11, Lubrizol Advanced Materials, Inc., USA) and loess powder (chemical composition: $58.8 \% \mathrm{SiO}_{2}, 21.0 \% \mathrm{Al}_{2} \mathrm{O}_{3}, 8.34 \%$ $\mathrm{Fe}_{2} \mathrm{O}_{3}, 0.04 \% \mathrm{CaO}, 0.28 \% \mathrm{MgO}, 1.00 \% \mathrm{TiO}_{2}, 2.35 \% \mathrm{~K}_{2} \mathrm{O}$, and $0.11 \% \mathrm{Na}_{2} \mathrm{O}$; ig. loss: $8.1 \%$ ) were used to produce composite nanofibers. The loess powder was obtained from HONGIK BIO TECH Co., Ltd. (Damyang-gun, Jeollanam-do, Republic of Korea). N,N-Dimethylformamide (DMF; Showa Chemical Co., Ltd., Japan) and methyl ethyl ketone (2-butanone) (MEK, extra pure; Junsei, Japan) were used as received without further purification. In VOC absorption experiments, three different kinds of gas (chloroform, benzene, and toluene) (purity 99.9\%, AR grade) were analyzed.

2.2. Fabrication of Composite Electrospun Mats. PU pellets were dried for at least $3 \mathrm{~h}$ in a dry oven at $80^{\circ} \mathrm{C}$ prior to dissolution in solvents. A $10 \mathrm{wt} \%$ PU solution in DMF/MEK ( $50: 50$ by weight) was prepared using a magnetic stirrer at $300 \mathrm{rpm}$ for $12 \mathrm{~h}$ at room temperature, and different amounts of $\operatorname{LP}(0,10,30$, and $50 \mathrm{wt} \%$ with respect to PU) were added to create a spinning nanosuspension using ultrasonication for $2 \mathrm{~h}$. This was followed by $2 \mathrm{~h}$ magnetic stirring at $300 \mathrm{rpm}$ under room temperature. Electrospinning was carried out using the setup shown in Figure 1. A total of $15 \mathrm{kV}$ of highvoltage electricity (New Era Pump Systems, Inc., NY, USA)

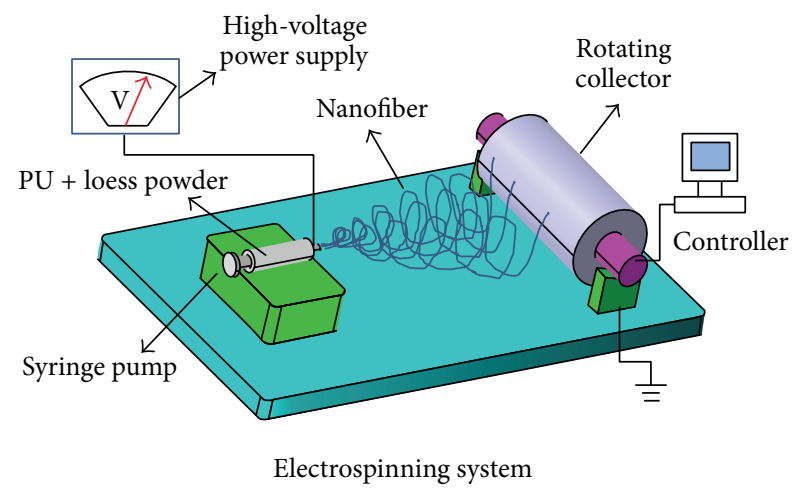

FIGURE 1: Schematic diagram of the electrospinning setup.

was applied to the PU/LP spinning nanosuspension in a syringe for electrospinning. The tip-to-collector distance was $18 \mathrm{~cm}$, and the nanosuspension feed rate was $1 \mathrm{~mL} / \mathrm{h}$. Finally, nanofibrous mats were dried under vacuum for $12 \mathrm{~h}$ at $60^{\circ} \mathrm{C}$ after electrospinning.

2.3. Characterization. The morphological structures of nanofibrous mats were characterized using field emission scanning electron microscopy (FE-SEM, JIB-4601F, JEOL, Japan) and biotransmission electron microscopy (Bio-TEM, H-7650, Hitachi, Japan). Fiber diameter was determined on 100 filaments or particles using Image (NIH, USA) software. The Fourier transform infrared spectroscopy (FTIR, Spectrum GX, Perkin Elmer, USA) spectra of samples were obtained using a Paragon 1000 spectrometer. $\mathrm{X}$-ray diffraction (XRD) analysis was carried out using a Multi-Purpose High Performance X-ray Diffractometer (X'pert Powder, PANalytical, Netherlands). Nanosuspension viscosity was measured using an EC meter (Brookfield, USA). An AMETEK tensile test machine (AMETEK, USA) measured the tensile properties of samples.

2.4. VOCs Absorption Experiment. For the VOC absorption experiment, pristine and composite electrospun $\mathrm{PU}$ matrices ( $0 \mathrm{wt} \% \mathrm{LP}, 10 \mathrm{wt} \% \mathrm{LP}, 30 \mathrm{wt} \% \mathrm{LP}$, and $50 \mathrm{wt} \% \mathrm{LP}$ ) were composed of $8 \mathrm{~cm} \times 8 \mathrm{~cm}$ fibers. The absorption experiment was implemented in a closed container with two valves. For every experiment, a rotary pump was used to remove impurities and other contaminants on the fiber surface and container. First, $100 \mathrm{mg}$ each of chloroform, benzene, and toluene were mixed. Then, methanol was used to dilute the nanosuspension to result in $2 \mathrm{mg}$ of VOCs. A syringe was used to inject $2 \mathrm{mg}$ of VOCs into the container and onto fiber surfaces, which were then allowed to evaporate for $1 \mathrm{~h}$ at room temperature. After that, unabsorbed VOCs were placed into a Tenax absorber (Tenax-GR; Japan Analytical Industry, Tokyo, Japan) using a nitrogen stream for 5 minutes. In this study, quantitative and qualitative analyses were performed using GC/MS (gas chromatography-mass spectroscopy, XEVO TQS, Waters, USA). A MS/FID in a purge and trap analyzer evaluated the Tenax-GR at $280^{\circ} \mathrm{C}$. VOCs were purged and trapped using Automated Purge \& Trap analyzer JTD-505II (Japan 
TABLE 1: Physical properties of PU/LP spinning solutions.

\begin{tabular}{lccccc}
\hline \multirow{2}{*}{ Spinning solution } & \multirow{2}{*}{ Viscosity $(\mathrm{cP})$} & \multicolumn{2}{c}{ Fiber diameter $(\mathrm{nm})$} & \multirow{2}{*}{ BET area $\left(\mathrm{m}^{2} / \mathrm{g}\right)$} & \multirow{2}{*}{ Tensile strength $(\mathrm{MPa})$} \\
\hline PU + LP 0 wt\% & 547 & $290-987$ & 636 & 5.9933 & $7.2 \pm 2.31$ \\
PU + LP 10 wt\% & 552 & $290-993$ & 526 & 1.3481 & $1.1 \pm 0.05$ \\
PU + LP 30 wt\% & 595 & $184-618$ & 343 & 2.6032 & $0.5 \pm 0.03$ \\
PU + LP 50 wt\% & 830 & $172-711$ & 368 & 2.2095 & - \\
\hline
\end{tabular}

Analytical Industry, Japan). Gas composition was analyzed by AGC/MS QP 2010 Plus (Shimadzu, Kyoto, Japan). More specific VOC absorption experimental methods are available in our previous article [23].

\section{Results and Discussion}

3.1. Morphological Characteristics of PU/LP Composite Fibers. In this study, the loess consisted of typical elements, such as $50 \% \mathrm{Si}, 25 \% \mathrm{Al}, 15 \% \mathrm{Fe}$, and $5 \% \mathrm{~K}$, and small amounts of $\mathrm{Ti}, \mathrm{Mg}$, and $\mathrm{Ba}$. Figure 2(a) shows FE-SEM images of LP, which was found to have irregular shapes with different sizes and diameters. Table 1 shows the physical properties of $\mathrm{PU}$ solution/mats containing different amounts of LP. Table 1 shows that the fibrous membranes had a wide diameter distribution. With increased content of LP, the fiber diameter clearly decreased. The smallest fiber diameter was produced when LP content increased to $30 \mathrm{wt} \%$, and the average diameter was about $343 \mathrm{~nm}$. Similar results have also been observed by other researchers [33-35]. However, when the LP content exceeded $30 \mathrm{wt} \%$, there was an increase in fiber diameter. This might be because the LP highly dissolved into PU solution to reach saturation when LP content increased to $30 \mathrm{wt} \%$.

FE-SEM images of PU/LP nanofibrous membranes with increased LP content are shown in Figure 2. Figures 2(b)2(e) show PU electrospun fibers containing $0,10,30$, and $50 \mathrm{wt} \% \mathrm{LP}$, respectively. Figure 2(b) is an FE-SEM image of PU solution without LP, showing a smooth and nonporous surface compared with those in Figures 2(c)-2(e). Different LP content dissolved in PU produced smooth or not smooth fiber surfaces. The smooth fiber surfaces produced by LP did not incorporate through electrospinning. However, the not smooth fiber surfaces produced by LP were highly disordered with agglomerated LP. Figure 2 also shows that fiber diameter decreased as LP content increased from $0 \mathrm{wt} \%$ to $30 \mathrm{wt} \%$. When LP content exceeded $30 \mathrm{wt} \%$, as shown in Figure 2(e), many LP particles gathered together and connected with PU, disturbing the fiber morphology. The increased viscosity of spinning solutions and gathering of LP particles at the nozzle results in increased fiber diameter and can lead to nozzle blockage during electrospinning. Figures 2(b)-2(e) show that PU solution with LP up to $30 \mathrm{wt} \%$ was spinnable, and $30 \mathrm{wt} \%$ LP dissolved in PU solution was a suitable amount for effective particle incorporation without disturbing fiber morphology through electrospinning. These figures also clearly show that the smoothness of fibers and homogeneous distribution of LP were excellent when LP content increased to $30 \mathrm{wt} \%$.
TEM images of PU/LP nanofibrous membranes are shown in Figure 3. Figure 3(a) is a pristine PU nanofiber that is beadless, cylindrical, and smooth. When adding the LP NPs into PU solution to produce composite fibers, shown in Figures 3(b)-3(d), LP NPs were either inside PU nanofibers (see Figure $3(\mathrm{c})$ ) or on the surfaces of fibers (see Figures 3(b) and 3(d)). LP NPs appeared inside the fiber because the LP content was less than the $50 \mathrm{wt} \%$ of LP in the PU solution, where there was a good degree of mixing, and the viscosity was not high. That is, the nanosuspension did not require significant energy during electrospinning. However, when increasing LP content to $50 \mathrm{wt} \%$, the viscosity of the PU/LP electrospinning nanosuspension became high. Electrospinning requires more energy to overcome surface tension, leading to more agglomeration of LP NPs and bead formation on PU nanofibers [20]. Agglomeration can also reduce the mechanical properties of composite nanofibers.

3.2. Mechanical Properties of PU/LP Composite Fibers. Loess has a good humidity-adjusting function and a far infrared ray radiation function, making it a very beneficial material for the human body. In cosmetics, loess has a whitening effect and strong affinity for the skin. It also can increase skin flexibility and waste discharge. In this study, loess was chosen for absorption of VOCs as a research material by adding it to electrospun fibers. We were interested in whether loess could improve the mechanical properties of PU fibers and act as a commercial air filter textile nanofibrous membrane with high VOC absorption efficiency. Table 1 and Figure 4 show the tensile strength of electrospun nanofibrous mats. The tensile strength of pristine PU nanofibrous mat was $7.2 \pm 2.31 \mathrm{MPa}$, while composite PU electrospun fibers contained 10 and $30 \mathrm{wt} \% \mathrm{LP}$ with $1.1 \pm 0.05$ and $0.5 \pm 0.03 \mathrm{MPa}$, respectively. However, there is no measured tensile strength of composite PU electrospun fibers containing $50 \mathrm{wt} \% \mathrm{LP}$. This is because its tensile strength was very small, and the fibers broke when performing the tensile strength test. It is clear from these results that tensile strength drastically decreased with increased amounts of LP in fibers. The tensile strength of composite PU electrospun fibers containing 10 and $30 \mathrm{wt} \%$ LP decreased by $85 \%$ and $93 \%$ compared with pristine PU electrospun fibers, respectively. With increased LP content in PU fibers, the mechanical properties of PU/LP composite mats were greatly reduced. Under the existing state without adding any tensile strength additives, PU/LP composite fibers produced by electrospinning would be difficult to use as a commercial air filter.

To analyze the composition of electrospun nanofibers and investigate possible interactions between PU and LP 


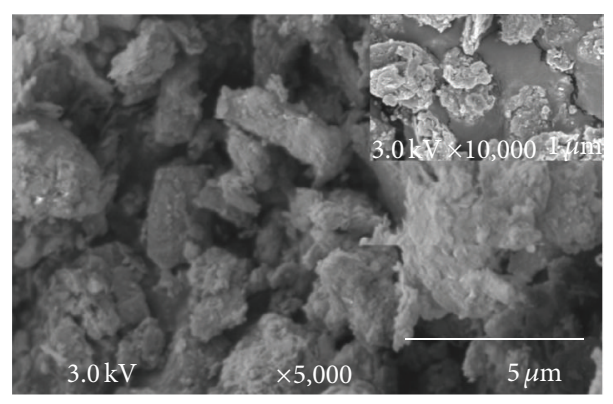

(a) LP

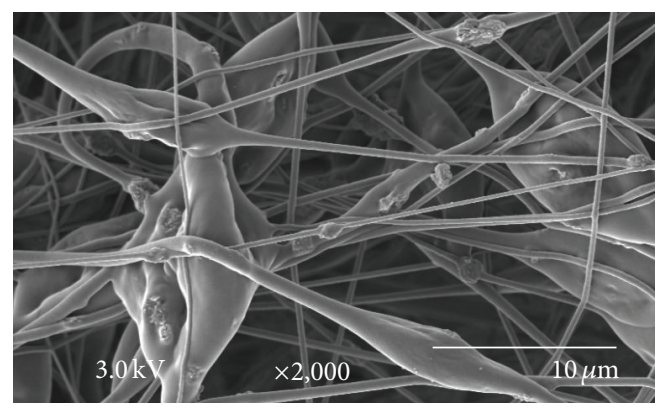

(c) $\mathrm{PU}+\mathrm{LP} 10 \mathrm{wt} \%$

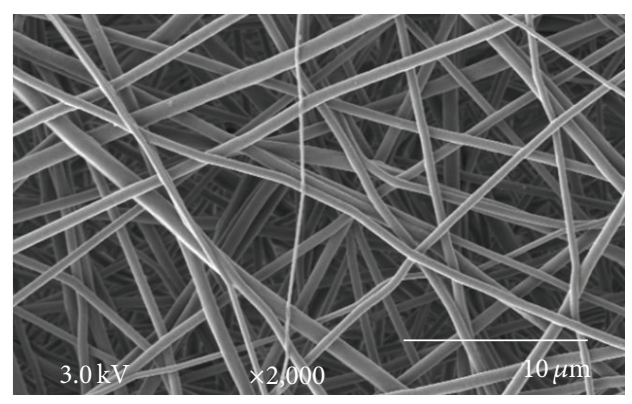

(b) PU + LP $0 w t \%$

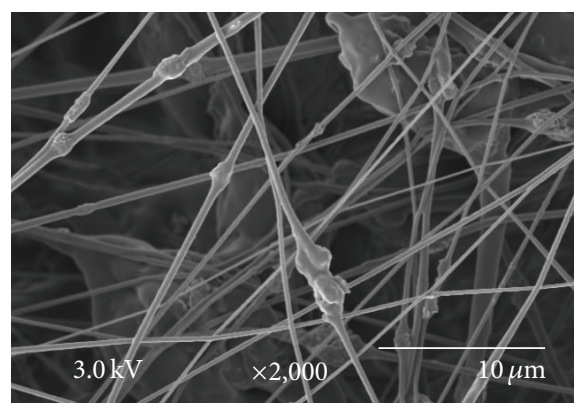

(d) $\mathrm{PU}+\mathrm{LP} 30 \mathrm{wt} \%$

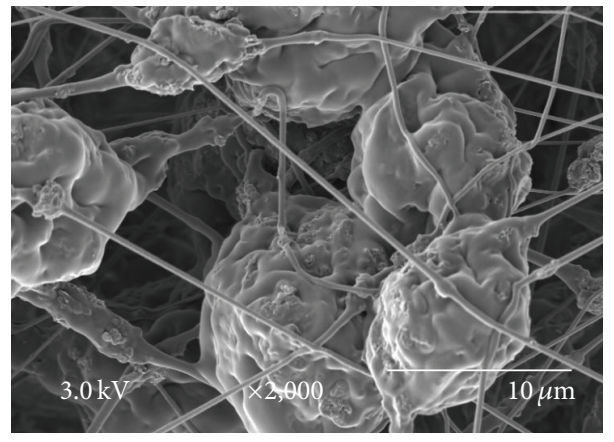

(e) PU + LP $50 w t \%$

Figure 2: FE-SEM images of PU/LP electrospun fibers containing 0, 10, 30, and $50 \mathrm{wt} \% \mathrm{LP}$.

NPs, the XRD and FTIR spectra of nanofibrous mats were investigated. The XRD patterns of nanofibrous mats are shown in Figure 5, which shows that, with increasing amount of LP in fibers, the relative intensity gradually increased. This finding demonstrates effective loading of LP NPs on the fiber surface. The patterns of all nanofibrous mats had different crystalline characteristic peaks, as shown in Figure 5. The $\gamma$-phase crystalline characteristic peaks of all nanofibrous mats are shown at a $2 \theta$ of about $21^{\circ}$. The $\gamma$-phase crystalline characteristic peaks appeared at almost the same location, indicating very little interaction between PU and LP NPs, similar to findings reported by Pant et al. [20]. The FTIR patterns of nanofibrous mats are shown in Figure 6, which shows many peaks. Bands at 3347, 2973, 2920, 1752, 1588, 1232, and $964 \mathrm{~cm}^{-1}$ of neat PU nanofibrous mats were assigned to stretching of the $\mathrm{N}-\mathrm{H}$ group, $\mathrm{CH}_{2}$ asymmetric vibration, $\mathrm{CH}_{3}$ symmetric vibration, stretching of the carbonyl group in hard segments, urethane amide II band, $\mathrm{C}(\mathrm{O})-\mathrm{O}-\mathrm{C}$ stretching of the hard segment, and bending vibration in a benzene ring, respectively [36]. These results are similar to those of our previous research [23]. In addition, the IR characteristic absorption peaks of PU/LP composite nanofibrous mats with different LP contents appeared in almost the same positions as those of neat PU nanofibrous mats. However, with increasing amount of LP in fibers, the bands shifted toward higher values, indicating molecular interactions between PU and LP NPs $[34,37,38]$.

\subsection{Absorption Characteristics of Different Nanofibrous Mats.} This study mainly investigates PU/LP composite nanofibrous mats produced by electrospinning for VOCs adsorption. Loess is an easy to obtain material with low cost that can be utilized for various applications. With excellent VOC absorption capacity, it can be widely used to remove harmful VOCs in new houses and new cars. The VOC absorption characteristics of composite PU mats containing different amounts of LP are shown in Figure 7. With increasing amount of LP, the VOC absorption capacity of PU/LP composite nanofibrous 


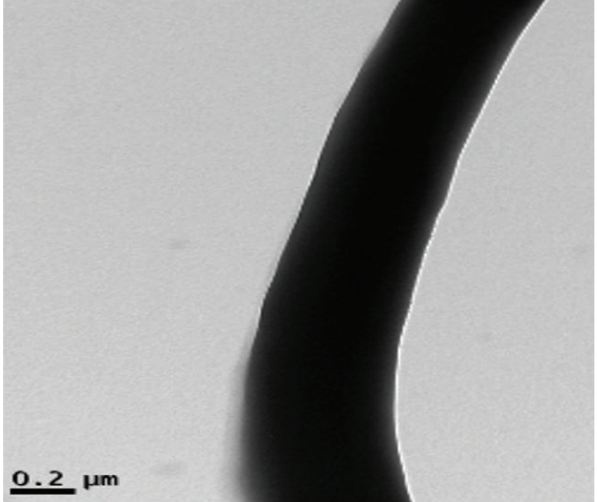

(a) PU + LP 0 wt $\%$

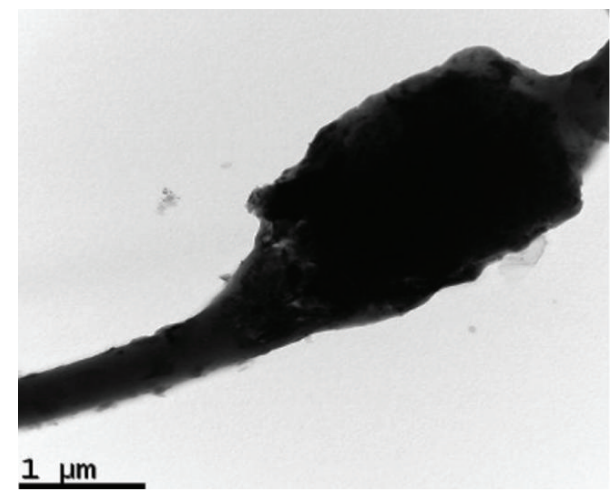

(c) PU + LP $30 w t \%$

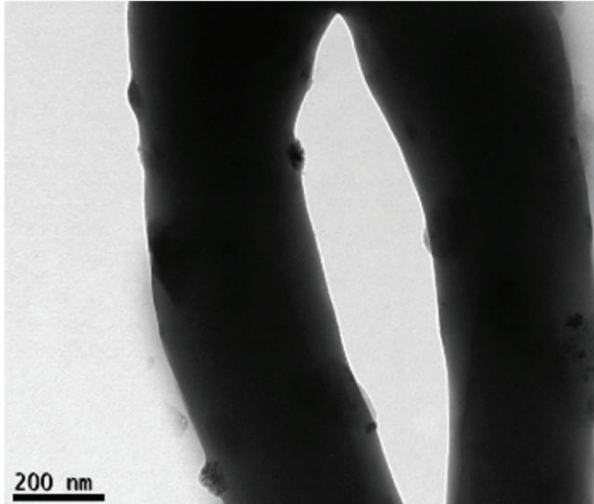

(b) PU + LP $10 w t \%$

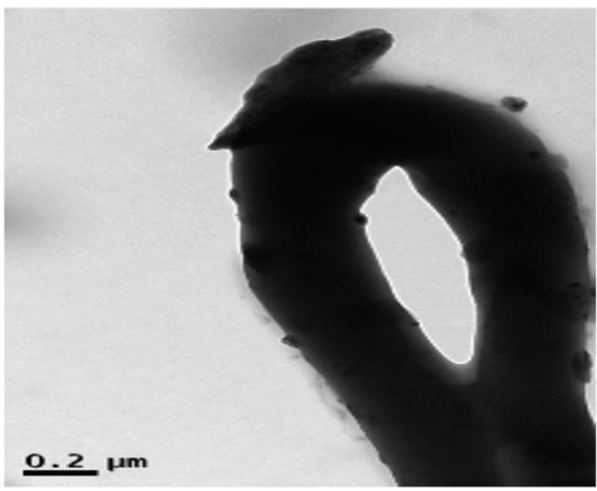

(d) PU + LP $50 w t \%$

Figure 3: TEM images of PU/LP electrospun fibers containing 0, 10, 30, and $50 \mathrm{wt} \% \mathrm{LP}$.

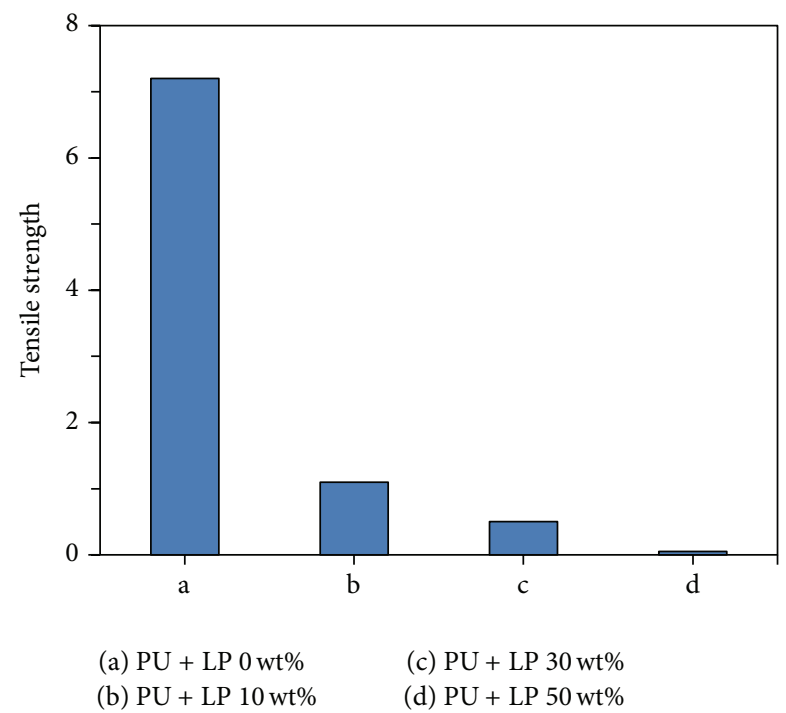

Figure 4: Tensile strength of electrospun PU mats with different amounts of LP.

mats increased compared to that of neat PU composite nanofibrous mats. These results can be explained by the decreasing fiber diameter of composite fibers with increasing amount of LP, increasing the surface area of composite fibers.

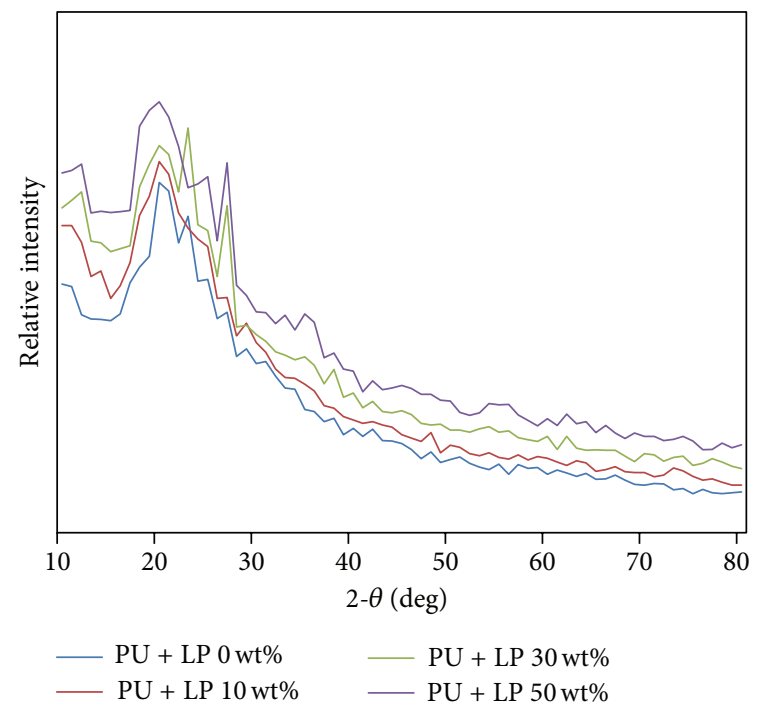

FIGURE 5: XRD patterns of different nanofibrous mats.

The LP NPs present on fiber surfaces increased the absorption capacity. Neat PU composite nanofibrous mats were also able to absorb VOCs [24]. The VOC absorption capacity of PU/LP nanofibers containing $10 \mathrm{wt} \%, 30 \mathrm{wt} \%$, and $50 \mathrm{wt} \%$ LP NPs increased by $55 \%, 300 \%$, and $192 \%$, respectively. The 


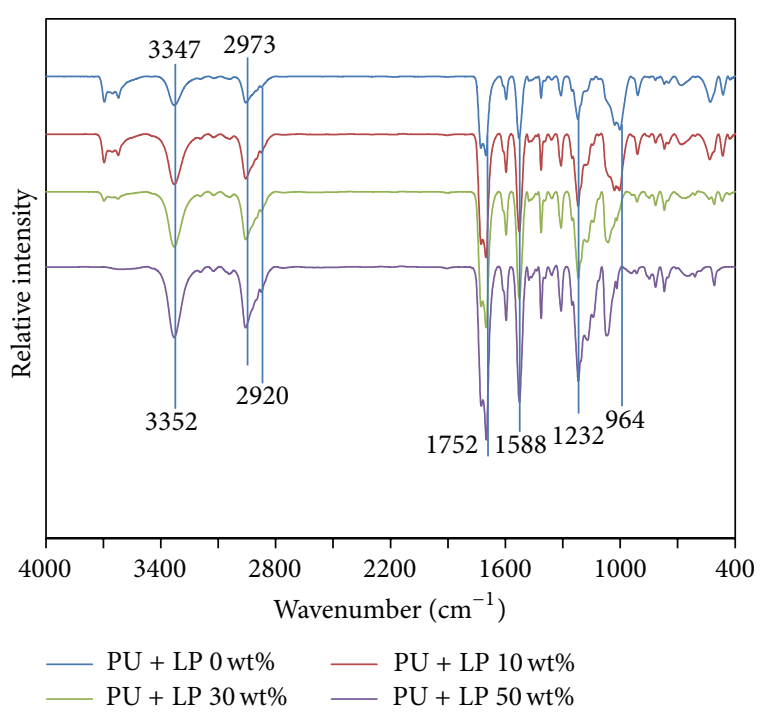

FIGURE 6: FTIR spectra of different nanofibrous mats.

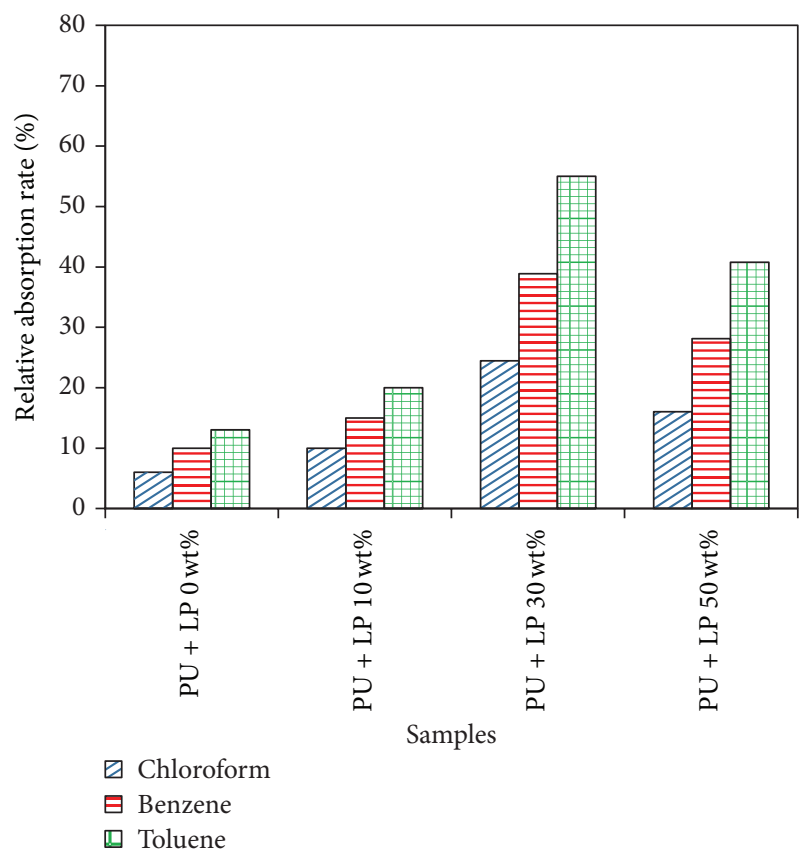

FIGURE 7: VOC absorption capacity of different nanofibrous mats.

VOC absorption capacity of PU mats containing $30 \mathrm{wt} \% \mathrm{LP}$ NPs was the highest because this concentration produced maximum LP-loaded smooth fibers and high BET surface area [23]. The BET surface area is shown in Table 1. When the concentration of LP in PU spinning nanosuspension was sufficiently large, extensive agglomeration of LP particles occurred, preventing homogeneous LP NP distribution in PU film. Therefore, a high concentration of LP will decrease VOC absorption capacity [22]. The VOC absorption capacity of PU/LP composite nanofibrous films showed a trend of toluene $>$ benzene $>$ chloroform. Kim et al. [23] reported similar results. PU/LP composite nanofibrous films have

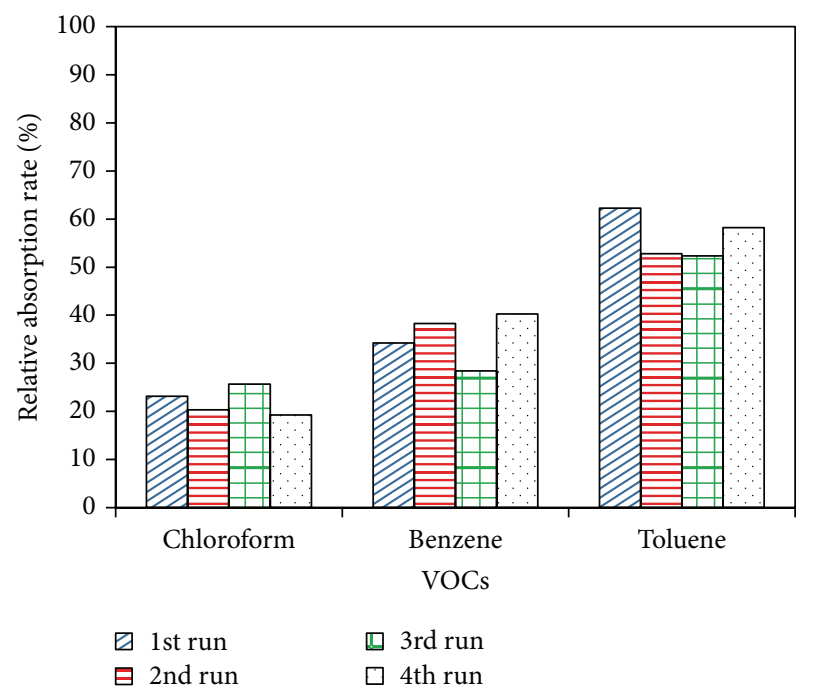

FIGURE 8: VOC absorption capacity of $30 \mathrm{wt} \%$ LPs containing PU film in different cycles.

different trends for different VOCs, which is related to the formation of $\pi$-complexes [39]. If the $\pi$-complex of PU/LP films is larger and more stable, the adsorption capacity of the surface for VOCs increases. Chloroform is not an aromatic compound, and its lack of $\pi$-complex formation leads to decreased VOC absorption capacity. Thus, its VOC absorption capacity is the smallest of the tested compounds. In addition, the adsorption capacity of a surface for VOCs is related to the ionization potential of the donor molecule. High ionization potential prevents charge transfer complexes from forming $[40,41]$. This property also explains the trend of toluene $>$ benzene $>$ chloroform.

To further demonstrate the reliability of the VOC absorption capacity of PU/LP films, this VOC absorption experiment was repeated four times using PU films containing $30 \mathrm{wt} \%$ LP. Figure 8 shows the results, which are nearly the same for all four cycles. This reliability also indicates that the PU/LP composite film had reversible absorption and desorption behavior.

\section{Conclusions}

In this study, we report that PU/LP composite films can be produced by electrospinning. FE-SEM and TEM images indicated that 10 and $30 \mathrm{wt} \%$ of LP NPs homogeneously disperse in a polymer matrix, while $50 \mathrm{wt} \%$ of $\mathrm{LP}$ forms some agglomeration on the film surface. With increased amount of LP, the viscosity of the spinning nanosuspension increased, also increasing the possibility that the nozzle will be blocked. With increased amount of LP, nanofiber diameter decreased and BET surface area increased. The highest VOC absorption capacity of PU/LP films was that of a film containing $30 \mathrm{wt} \%$ LP. Due to its high VOC absorption capacity, this film can be used for VOC absorption in new houses and cars. 


\section{Competing Interests}

The authors declare that there are no competing interests regarding the publication of this paper.

\section{Acknowledgments}

This research was supported by the Basic Science Research Program through the National Research Foundation of Korea (NRF) funded by the Ministry of Education (Project no. 2014059723)

\section{References}

[1] Z.-M. Huang, Y.-Z. Zhang, M. Kotaki, and S. Ramakrishna, "A review on polymer nanofibers by electrospinning and their applications in nanocomposites," Composites Science and Technology, vol. 63, no. 15, pp. 2223-2253, 2003.

[2] S. Ramakrishna, K. Fujihara, W.-E. Teo, T. Yong, Z. Ma, and R. Ramaseshan, "Electrospun nanofibers: solving global issues," Materials Today, vol. 9, no. 3, pp. 40-50, 2006.

[3] D. H. Reneker, A. L. Yarin, H. Fong, and S. Koombhongse, "Bending instability of electrically charged liquid jets of polymer solutions in electrospinning," Journal of Applied Physics, vol. 87, no. 9, pp. 4531-4547, 2000.

[4] A. Greiner and J. H. Wendorff, "Electrospinning: a fascinating method for the preparation of ultrathin fibers," Angewandte Chemie International Edition, vol. 46, no. 30, pp. 5670-5703, 2007.

[5] N. Bhardwaj and S. C. Kundu, "Electrospinning: a fascinating fiber fabrication technique," Biotechnology Advances, vol. 28, no. 3, pp. 325-347, 2010.

[6] H. J. Kim, H. R. Pant, C. H. Park, L. D. Tijing, N. J. Choi, and C. S. Kim, "Hydrothermal growth of mop-brush-shaped $\mathrm{ZnO}$ rods on the surface of electrospun nylon-6 nanofibers," Ceramics International, vol. 39, no. 3, pp. 3095-3102, 2013.

[7] Y. Dzenis, "Spinning continuous fibers for nanotechnology," Science, vol. 304, no. 5679, pp. 1917-1919, 2004.

[8] S. J. Kim, Y. J. Kang, and N.-J. Choi, "Optical-fiber electronic speckle pattern interferometry for quantitative measurement of defects on aluminum liners in composite pressure vessels," Journal of the Optical Society of Korea, vol. 17, no. 1, pp. 50-56, 2013.

[9] K. Saeed, S. Haider, T.-J. Oh, and S.-Y. Park, "Preparation of amidoxime-modified polyacrylonitrile (PAN-oxime) nanofibers and their applications to metal ions adsorption," Journal of Membrane Science, vol. 322, no. 2, pp. 400-405, 2008.

[10] P. Raghavan, X. H. Zhao, J.-K. Kim et al., "Ionic conductivity and electrochemical properties of nanocomposite polymer electrolytes based on electrospun poly(vinylidene fluoride-cohexafluoropropylene) with nano-sized ceramic fillers," Electrochimica Acta, vol. 54, no. 2, pp. 228-234, 2008.

[11] S. G. Kumbar, S. P. Nukavarapu, R. James, L. S. Nair, and C. T. Laurencin, "Electrospun poly(lactic acid-co-glycolic acid) scaffolds for skin tissue engineering," Biomaterials, vol. 29, no. 30, pp. 4100-4107, 2008.

[12] H.-F. Wen, C. Yang, D.-G. Yu, X.-Y. Li, and D.-F. Zhang, "Electrospun zein nanoribbons for treatment of lead-contained wastewater," Chemical Engineering Journal, vol. 290, pp. 263272, 2016
[13] D. G. Yu, C. Yang, M. Jin et al., "Medicated Janus fibers fabricated using a Teflon-coated side-by-side spinneret," Colloids and Surfaces B: Biointerfaces, vol. 138, pp. 110-116, 2016.

[14] D.-G. Yu, X.-Y. Li, X. Wang, J.-H. Yang, S. W. A. Bligh, and G. R. Williams, "Nanofibers fabricated using triaxial electrospinning as zero order drug delivery systems," ACS Applied Materials and Interfaces, vol. 7, no. 33, pp. 18891-18897, 2015.

[15] I. G. Kim, J.-H. Lee, A. R. Unnithan, C.-H. Park, and C. S. Kim, "A comprehensive electric field analysis of cylinder-type multi-nozzle electrospinning system for mass production of nanofibers," Journal of Industrial and Engineering Chemistry, vol. 31, pp. 251-256, 2015.

[16] C. Burger, B. S. Hsiao, and B. J. Chu, "Nanofibrous materials and their applications," Annual Review of Materials Research, vol. 36, pp. 333-368, 2006.

[17] M. M. Demir, I. Yilgor, E. Yilgor, and B. Erman, "Electrospinning of polyurethane fibers," Polymer, vol. 43, no. 11, pp. 33033309, 2002.

[18] D. Aussawasathien, C. Teerawattananon, and A. Vongachariya, "Separation of micron to sub-micron particles from water: electrospun nylon-6 nanofibrous membranes as pre-filters," Journal of Membrane Science, vol. 315, no. 1-2, pp. 11-19, 2008.

[19] H. J. Kim, H. R. Pant, C. H. Park et al., "Electrical properties of $\mathrm{ZnO} /$ nylon-6 spider-wave-like nanonets prepared via electrospinning," Digest Journal of Nanomaterials and Biostructures, vol. 8, pp. 385-393, 2013.

[20] H. R. Pant, M. P. Bajgai, K. T. Nam et al., "Electrospun nylon6 spider-net like nanofiber mat containing $\mathrm{TiO}_{2}$ nanoparticles: a multifunctional nanocomposite textile material," Journal of Hazardous Materials, vol. 185, no. 1, pp. 124-130, 2011.

[21] H. R. Pant, D. R. Pandeya, K. T. Nam, W.-I. Baek, S. T. Hong, and H. Y. Kim, "Photocatalytic and antibacterial properties of a $\mathrm{TiO}_{2}$ /nylon-6 electrospun nanocomposite mat containing silver nanoparticles," Journal of Hazardous Materials, vol. 189, no. 1-2, pp. 465-471, 2011.

[22] H. J. Kim, H. R. Pant, N. J. Choi, and C. S. Kim, "Fly ash/polyurethane thin film for the adsorption of volatile organic compounds (VOCs) from air," Fibers and Polymers, vol. 15, no. 7, pp. 1393-1398, 2014.

[23] H. J. Kim, H. R. Pant, N. J. Choi, and C. S. Kim, "Composite electrospun fly ash/polyurethane fibers for absorption of volatile organic compounds from air," Chemical Engineering Journal, vol. 230, pp. 244-250, 2013.

[24] E. Scholten, L. Bromberg, G. C. Rutledge, and T. A. Hatton, "Electrospun polyurethane fibers for absorption of volatile organic compounds from air," ACS Applied Materials and Interfaces, vol. 3, no. 10, pp. 3902-3909, 2011.

[25] I. Jarraya, S. Fourmentin, M. Benzina, and S. Bouaziz, "VOC adsorption on raw and modified clay materials," Chemical Geology, vol. 275, no. 1-2, pp. 1-8, 2010.

[26] F. Qu, L. Z. Zhu, and K. Yang, "Adsorption behaviors of volatile organic compounds (VOCs) on porous clay heterostructures (PCH)," Journal of Hazardous Materials, vol. 170, no. 1, pp. 712, 2009.

[27] L. Zhu, S. Tian, and Y. Shi, "Adsorption of volatile organic compounds onto porous clay heterostructures based on spent organobentonites," Clays and Clay Minerals, vol. 53, no. 2, pp. 123-136, 2005.

[28] J. H. Park and D. I. Jung, "Removal of total phosphorus (TP) from municipal wastewater using loess," Desalination, vol. 269, no. 1-3, pp. 104-110, 2011. 
[29] S. S. Tahir and N. Rauf, "Thermodynamic studies of Ni(II) adsorption onto bentonite from aqueous solution," Journal of Chemical Thermodynamics, vol. 35, no. 12, pp. 2003-2009, 2003.

[30] B. Koumanova and P. Peeva-Antova, "Adsorption of pchlorophenol from aqueous solutions on bentonite and perlite," Journal of Hazardous Materials, vol. 90, no. 3, pp. 229-234, 2002.

[31] T. An, H. Chen, H. Zhan, K. Zhu, and R. Berndtsson, "Sorption kinetics of naphthalene and phenanthrene in loess soils," Environmental Geology, vol. 47, no. 4, pp. 467-474, 2005.

[32] T. B. İyim and G. Güçlü, "Removal of basic dyes from aqueous solutions using natural clay," Desalination, vol. 249, no. 3, pp. 1377-1379, 2009.

[33] F. A. Sheikh, N. A. M. Barakat, M. A. Kanjwal et al., "Electrospun antimicrobial polyurethane nanofibers containing silver nanoparticles for biotechnological applications," Macromolecular Research, vol. 17, no. 9, pp. 688-696, 2009.

[34] L. D. Tijing, M. T. G. Ruelo, A. Amarjargal et al., "Antibacterial and superhydrophilic electrospun polyurethane nanocomposite fibers containing tourmaline nanoparticles," Chemical Engineering Journal, vol. 197, pp. 41-48, 2012.

[35] W. K. Son, J. H. Youk, T. S. Lee, and W. H. Park, “The effects of solution properties and polyelectrolyte on electrospinning of ultrafine poly(ethylene oxide) fibers," Polymer, vol. 45, no. 9, pp. 2959-2966, 2004.

[36] A. S. Khan, Z. Ahmed, M. J. Edirisinghe, F. S. L. Wong, and I. U. Rehman, "Preparation and characterization of a novel bioactive restorative composite based on covalently coupled polyurethane-nanohydroxyapatite fibres," Acta Biomaterialia, vol. 4, no. 5, pp. 1275-1287, 2008.

[37] C. Zhou, R. Chu, R. Wu, and Q. Wu, "Electrospun polyethylene oxide/cellulose nanocrystal composite nanofibrous mats with homogeneous and heterogeneous microstructures," Biomacromolecules, vol. 12, no. 7, pp. 2617-2625, 2011.

[38] G. P. Dong, X. D. Xiao, X. F. Liu et al., "Preparation and characterization of Ag nanoparticle-embedded polymer electrospun nanofibers," Journal of Nanoparticle Research, vol. 12, no. 4, pp. 1319-1329, 2010.

[39] J. Völter, "A $\pi$-complex mechanism for catalytic hydrogenation of the benzene ring," Journal of Catalysis, vol. 3, no. 3, pp. 297298, 1964.

[40] T. T. Phuong, J. Massardier, and P. Gallezot, "Competitive hydrogenation of benzene and toluene on group VIII metals: correlation with the electronic structure," Journal of Catalysis, vol. 102, no. 2, pp. 456-459, 1986.

[41] S. B. Lee, K. W. Chung, I. K. Hong, and H. J. Kim, "Selective catalytic oxidation of volatile organic solvent mixtures," Journal of Industrial and Engineering Chemistry, vol. 7, pp. 193-198, 2001. 

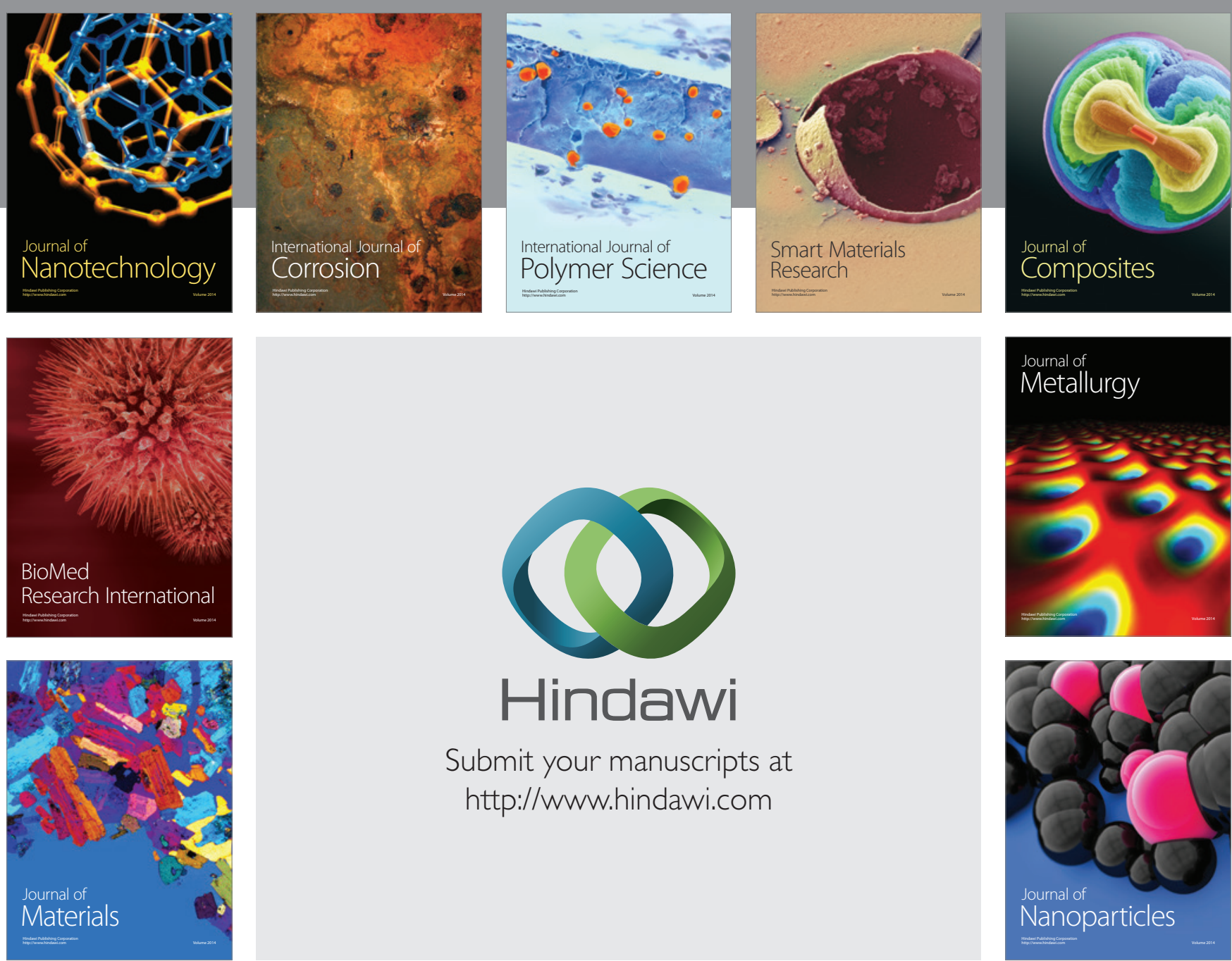

\section{Hindawi}

Submit your manuscripts at

http://www.hindawi.com

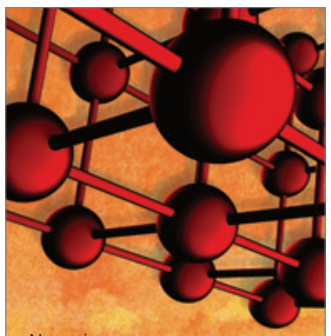

Materials Science and Engineering
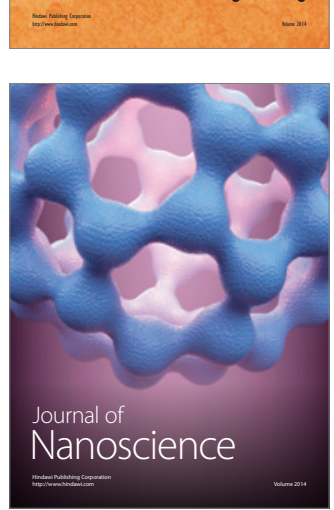
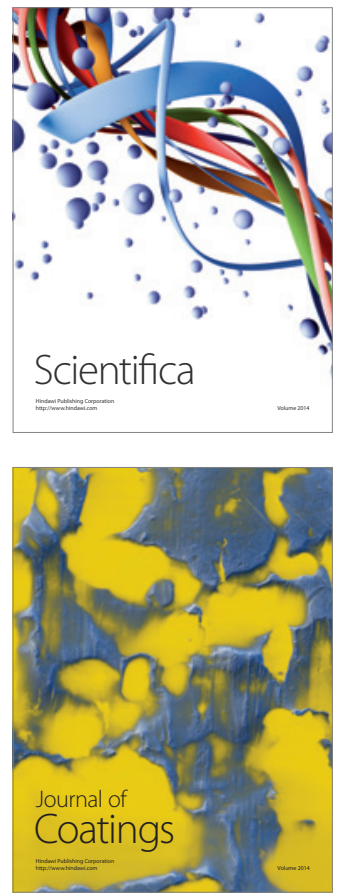
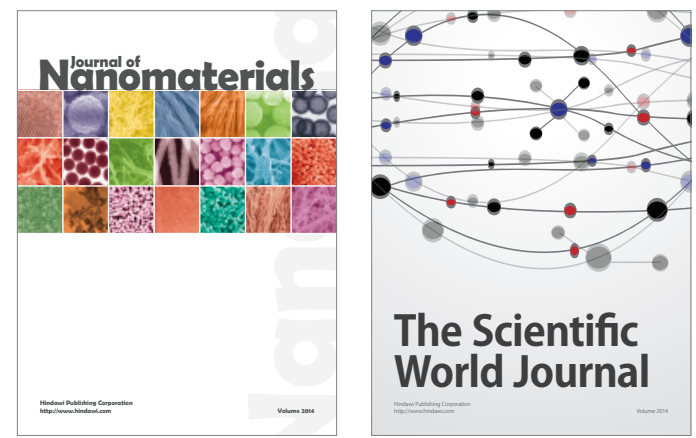

The Scientific World Journal
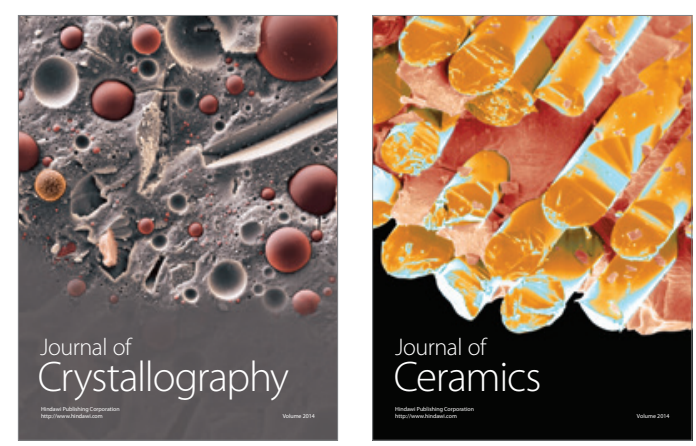
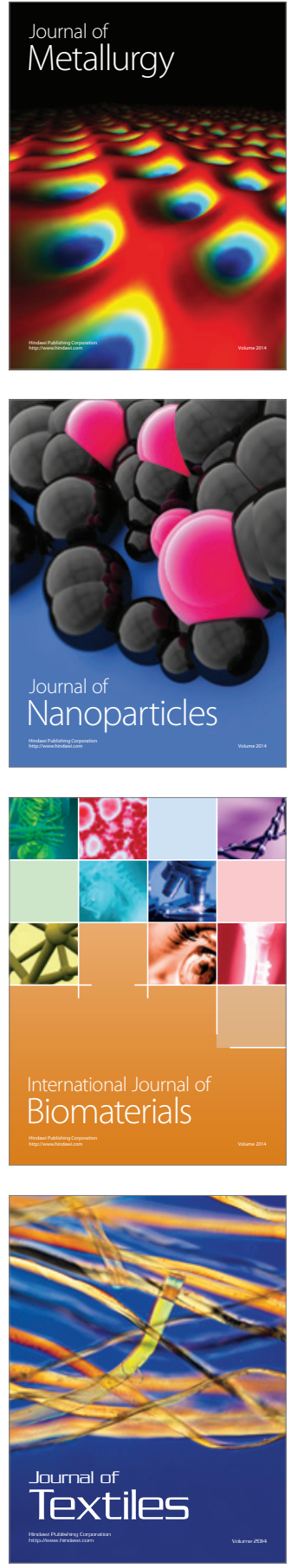